\title{
Clinical, diagnostic and therapeutic aspects of the epiploic appendagitis
}

\begin{abstract}
Background: The Epiploic Appendagitis is an uncommon pathology arising from the torsion or spontaneous venous thrombosis of the veins responsible for the drainage of the apoptotic appendages.

Aim: The purpose of this research is to report the characteristics of this disease. Method: The review includes articles published in papers indexed in the Scielo and PubMed databases over the last eight years (2008-2016). The following headings were crossing: Epiploic Appendagitis, differential diagnosis of Appendagitis and diagnostic methods of Appendagitis, and their respective literal translations in English, were selected 26 articles, used for database.

Results: Although there is discordance in the literature, the male sex is more frequently affected by this pathology. The characteristic manifestation is acute non-migratory abdominal pain, most often located in the lower left quadrant of the abdomen. The diagnosis is made from images from the Computed Tomography. The treatment occurs outpatient and provides for administration of analgesic and anti-inflammatory. Conclusion: A correct initial approach avoids invasive and unnecessary procedures
\end{abstract}

Volume 5 Issue $3-2018$

\author{
Denise Camilios Cossiolo, Rodrigo Eik \\ Sahyun, Kellyn Garbuio da Silva, Marco \\ Aurelio Cruciol Rodrigues, Emanuel Gois \\ Junior, Helio Aparecido Batistela Junior, Naja \\ Nabut \\ School of Medicine, Catholic University of Paraná, Brazil
}

Correspondence: Denise Camilios Cossiolo, School of Medicine, Catholic University of Paraná,Av. Jockey Club, 485 Hipica, Londrina - PR, Brazil,Tel (43) 999462733, Email deniseccossiolo@gmail.com

Received: March 26, 2018 | Published: May 16, 2018

Keywords: tomography, differentials diagnostics, appendicitis

\section{Introduction}

The Epiploic Appendagitis (EA) consists of a rare, benign, selflimiting clinical condition and accounts for $1 \%$ of all causes of acute abdominal pain in adults. ${ }^{1,2}$ It is an inflammatory pathology coming from the torsion or spontaneous venous thrombosis of vessels that drain the epiploic appendages. ${ }^{3}$ The Epiploic appendices are pedunculated structures of adipose content that protrude from the serous surface of the colon. ${ }^{4}$ This disease presents some synonyms such as: Epiploic Appendagitis, Epiploic Appendicitis, Hemorrhagic Epiploitite and Epiplopericolitis. ${ }^{3}$ The most classic clinical manifestation is acute and localized abdominal pain. It may present a defensive posture and peritoneal reaction on physical examination, mimicking acute abdomen. ${ }^{2,5}$

Before, the diagnosis of EA was performed by laparotomy. However, with the development of radiological technology, such as Ultrasonography or Computed Tomography (CT), allowed its distinction in the preoperative. ${ }^{6}$ The treatment is conservative and outpatient with administration of analgesics, anti-inflammatories. ${ }^{7,8}$ The objective of this review is to portray the clinical aspects, the diagnostic methods and the treatment of this rare and little discussed pathology.

\section{Methodology}

The literature review focused on journals indexed in the Scielo and Pub Med databases and used national and international studies published in the last eight years (2008-2016). The keywords used in the search were: Epiploic Appendagitis, Differential Diagnosis of Appendagitis and Diagnostic Methods of Appendagitis, and their respective literal translations in English. The inclusion criterion was all recent articles that portrayed the subject.

\section{Results}

\section{Anatomy}

The description of the Epiploic Appendages was first performed by Versalius in 1543. However, the pathology Appendagitis was only recognized in 1956 by Linn. The appendages, on the other hand, are projections of the external surface of the colon, replete with adipose content, covered by serosa and projecting into the peritoneal cavity. ${ }^{3}$ There have been reports of small bowel EA, although they are rare. ${ }^{9}$ The function of the epiploic appendages has not yet been well established, however, a defense role has already been described, such as that performed by large omentum. These structures are suggested to exhibit bacteriostatic properties. In addition, the appendages can function as a fat storage site used in prolonged periods of food deprivation. ${ }^{10}$

The development of epiploic appendages begins in the second trimester of intrauterine life, reaching considerable size only after puberty. ${ }^{5}$ There are approximately 50-100 appendages arranged along the colon. However, they are more frequently found in the sigmoid $(57 \%)$, followed by cecum $(26 \%)$, ascending colon $(9 \%)$, transverse colon $(6 \%)$ and descending colon $(2 \%){ }^{3,11}$ They are not commonly found in reto. ${ }^{4}$

Its length varies from $0.5-5 \mathrm{~cm}$ and its wall thickness is $1-2 \mathrm{~cm}$. The pedunculated appearance is due to vascular stem. ${ }^{4}$ Each appendages receives blood supply from one or two branches of terminal arteries formed in the straight vasa of the colon, being drained by a single tortuous vein which passes through its narrow pedicle. ${ }^{11,12}$ The ischemic symptoms of EA are initially caused by the venous component. ${ }^{4}$ Thus, this blood supply, associated with the pedunculated form, excessive mobility transforms the appendages into structures prone to torsion, ischemia or even hemorrhagic infarction and spontaneous venous thrombosis of a drainage vein..$^{5,6}$ 


\section{Pathophysiology}

However there is no definite etiological confirmation, EA is attributed to ischemia or thrombosis of the epiploic appendages. Usually, the torsion occurs in the vascular stem, followed by inflammation. ${ }^{5}$ Torsion of an appendage, followed by acute ischemia can cause necrosis of its adipose content, inflammation and localized peritoneal irritation. ${ }^{13}$ The twisting of the appendages is predisposed by limited blood supply, by pedunculated form, by bulbous configuration, and high mobility. ${ }^{10}$

Other causes such as bowel obstruction, hernia incarceration, lymphoid hyperplasia and bacterial invasion secondary to an abdominal infection have already been described. ${ }^{4,5}$ The evaluation of the dried appendages of patient with EA revealed the presence of inflammatory cells and colon bacteria. These bacteria may be responsible for the formation of localized abscesses and generalized peritonitis, rare secondary complications of AE. ${ }^{10}$

The secondary EA is the development of inflammation in a healthy epiploic appendage due to another pathological process such as bacterial infection in adjacent organ, for example, diverticulitis; appendicitis or cholecystitis. ${ }^{10}$ The diverticulitis is the most frequent cause of secondary EA by the the proximity of the diverticulum with the epiploic appendages. The secondary EA is not clinically relevant, its resolution occurs as the treatment of the underlying disease. ${ }^{10}$

The predicted risk factors include: hernia, obesity, rapid weight loss, and strenuous exercise. ${ }^{4,10}$ In the research developed by Martinez et al. ${ }^{11}$ the majority of patients with EA was obese or lost weight sharply in a short period of time. In this same research was also cited a study in which the patients with EA had a body mass index (BMI) $>25.9$ with deviation of $\pm 3.5 \mathrm{~kg} / \mathrm{m}^{2}$, significantly higher when compared to patients with acute diverticulitis. ${ }^{16}$

\section{Epidemiology}

The EA occurs mainly in men $(70-85 \%$ of cases) between the fourth and fifth decade of life. This pathology has a higher incidence around 40 years, a younger age when compared to patients with Acute Diverticulitis in sigmoid. ${ }^{11}$ In addition, reports of EA in children are very rare. ${ }^{8}$ There is evidence in the literature which reveals that men are affected almost five times more than women $(82 \% x 18 \%$ respectively). However, Szunyogh et al. found an abnormally high incidence in females. ${ }^{8}$ While, Freitas et al. admits that the incidence is the same for both sexes. ${ }^{3}$

\section{Clinical manifestations}

The most frequent presentation consists of sudden abdominal pain, non-migratory, which gets worse with cough or stretching of abdominal wall muscles. It is preferably located in the lower left quadrant $(73 \%-93 \%)$ when compared to the right $(7 \%-21 \%)$ or in epigastric region $(2 \%$ to $5 \%) .^{11,14}$ This is probably due to a higher incidence of EA in the sigmoid. ${ }^{11}$

Freitas et al. reported that the time of evolution of abdominal pain before the definitive diagnosis ranged from one to five days, with a median duration of three days. ${ }^{3}$ Symptoms such as change in stool frequency $(19.4 \%)$, fever $(15 \%)$, nausea $(12.9 \%)$, anorexia $(9.7 \%)$ and vomiting $(3.2 \%)$ are uncommon. ${ }^{11}$

In secondary EA, pain may be associated with the location of the underlying pathology, such as diverticulitis, cholestasis, and appendicitis. ${ }^{10}$ The physical examination reveals pain to the superficial and deep abdominal palpation, which is more intense at the site affected by the AE. ${ }^{11}$ The Epiploic Appendagitis can simulate an acute appendicitis or acute diverticulitis depending on the side which pain manifests, but usually fever, chills and leukocytosis are absent., ${ }^{415}$

\section{Diagnosis}

Before the implantation of the CT, the diagnosis was made intraoperatively. ${ }^{4}$ The first tomographic description of EA was performed by Danielson et al. Most cases reported in the literature were diagnosed after retrospective revaluation of CT images. ${ }^{10}$ The sigmoid and cecum are the regions with the highest incidence of EA. ${ }^{11}$ Approximately $57 \%$ of the cases are located in the sigmoid and $26 \%$ in the cecum. ${ }^{16}$

\section{Tomographic Findings}

The most frequent characteristics of this pathology in $\mathrm{CT}$ are paracolic oval mass, from 1 to $5 \mathrm{~cm}$, hypodense, with adipose content delimited by a halo with greater attenuation (the signal of the hiperatenuante ring), which is believed to portray the thrombosed appendage vessel (Figure 1). ${ }^{3,4,13,16,17}$ A thickening of the parietal peritoneum can be observed, caused by the inflammatory process ${ }^{18}$. The thickness of the colon wall is usually not altered. ${ }^{8}$

The infarcted appendages, most of the time, exhibit an egg shell calcification. Its smooth surface and its calcified consistency allow distinguishing EA from malignant lesion., ${ }^{3,18}$ These calcified appendages appear in the abdominal cavity. If tomography is performed for follow-up, it may show a varying degree of abnormal images within a month of evolution and complete resolution of the signals occurs within six months. ${ }^{19}$ It has also been reported that postinfarction appendages (calcified or not) can be found accidentally not only in the colon, but as free intraperitoneal bodies. ${ }^{3,18}$

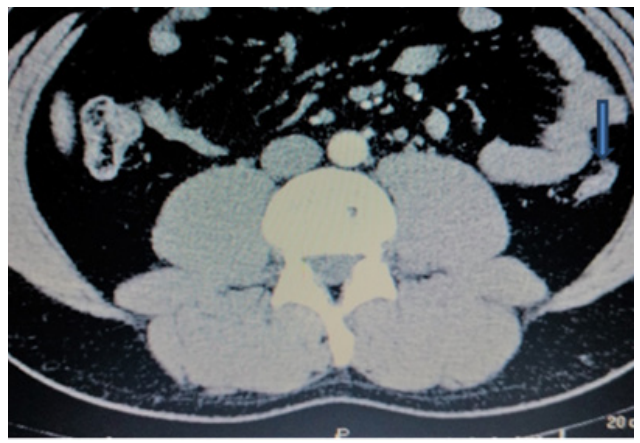

Figure I Oval image in the left colon, it's typical of Epiploic Appendagitis (blue arrow)

\section{Ultrasound findings}

The abdominal ultrasonography reveals an image of pericolonic oval mass, hyperechoic and non-compressible, often wrapped around a hypoechoic edge. ${ }^{8,19}$ The EA is usually an ischemic event, therefore, central hypoflow is observed in color Doppler. ${ }^{7}$ In addition, thickening of the bowel wall or compression in $21 \%$ with EA patients was revealed in a study using color Doppler ultrasonographic findings.

\section{Magnetic resonance findings}

The Magnetic Resonance can provide a precise diagnosis, but it is not the modality of choice. Both T1 and T2 reveal a mass with fat density attached to the colon. ${ }^{16}$ 


\section{Laboratory}

There are no pathognomonic laboratory findings for the diagnosis of EA. ${ }^{11}$ The laboratory findings that may be found leukocytes and PCR slightly increased. ${ }^{16}$ In the study developed by Freitas et al. alterations in urinary sediment were found in $5 \%$ of the sample. ${ }^{4}$

\section{Differential diagnostics}

The differential diagnoses of EA encompass clinical or surgical conditions which can progress to an acute inflammatory abdomen. ${ }^{11}$ The most frequent differential diagnoses found in CT include: Omental Infarction, Panniculitis Mesenteric, Acute Appendicitis and Diverticulitis. It was reported that of patients with suspected Acute Light Diverticulitis and Appendicitis in 7\% and $1 \%$ of the cases could be EA respectively. ${ }^{16}$

Some characteristics aid in the distinction between these pathologies and EA. For example, diverticulitis, despite presenting similar manifestations as those found in EA, tends to increase its frequency with age. ${ }^{12,18}$ Patients with diverticulitis are more likely to experience nausea, vomiting, fever and more diffuse abdominal pain. It presents mostly leukocytosis, and in the CT there is a long segment of the colon with a thickened wall, while in the EA the segment involved is short. ${ }^{12}$

The omental infarction is more prevalent in pediatric patients. ${ }^{20}$ The CT scan does not present a hyperattenuating ring, is usually a lesion larger than that of the EA (on average with a diameter of up to $7 \mathrm{~cm}$ ), is centered in the omentum and is usually located in the medial region of the cecum or the ascending colon. In addition, pain is localized preferentially on the right side of the abdomen. ${ }^{12}$

The acute appendicitis occurs in any age group, unlike EA that affects adults ( $>20$ years). ${ }^{12}$ In appendicitis it presents periumbilical pain with migration and signs of peritoneal irritation in the lower right quadrant, associated with anorexia and nausea. ${ }^{12,21}$ Acute appendicitis consists of a pathology whose diagnosis is eminently clinical. ${ }^{22}$ But, its diagnosis can also be given with the identification of an abnormal, dilated appendage (diameter $\geq 6 \mathrm{~mm}$ ), with thickened walls associated with pericecal inflammation in imaging tests such as CT. ${ }^{12,23}$

The mesenteric panniculitis may occur in all age groups, but mainly between the sixth and seventh decade of life. ${ }^{24}$ This pathology may be asymptomatic, but the possible clinical manifestations related to the inflammatory process or mass effect includes: acute abdominal pain, fever, nausea, vomiting, diarrhea and weight loss. The CT findings of panniculitis mesenteric include a focal area of increased attenuation within the mesenteric fat surrounded by a thin pseudocapsule, generally oriented to the left side. ${ }^{12}$ The tomographic differences present among the aforementioned pathologies are set out in the table 1 below:

The other possible differential diagnoses are: sclerosing mesenteritis, tumor or metastasis involving the mesocolon, cholecystitis, ovarian torsion, ovarian cyst rupture, ectopic pregnancy, pelvic inflammatory disease, ureteral lithiasis, gastritis, Crohn's disease, ulcerative rectocolitis and mesenteric adenitis. ${ }^{4,16}$ The correct diagnosis of EA is important for physicians to avoid unnecessary hospitalizations, antibiotic therapy, surgical interventions and excessive use of resources. ${ }^{6}$
Table I Tomographic changes that contribute to differential diagnosis

\section{Omental Infarct}

Without hyperattenuating ring, lesions with larger diameters and located in the medial region of the cecum or ascending colon.

\section{Appendicite Acute}

Presence of cecal appendages (diameter $\geq 6 \mathrm{~mm}$ ) dilated, thickened wall associated with pericecal inflammation.

\section{Mesenteric Panniculitis}

Focal area with increased attenuation inside the mesenteric fat, surrounded by a thin pseudocapsule.

\section{Diverticulitis}

Long segment of the colon and thickening of the wall.

\section{Epiploic Appendagitis}

Hyperatenuating ring, region, mainly in sigmoid.

\section{Epiploic Appendagitis}

\section{Presence de epiploic} appendages (diameter from I to $5 \mathrm{~cm}$ ) hypodense, with hyperattenuating ring, predominantly in the sigmoid region.

\section{Epiploic Appendagitis}

Paracolic oval mass, hypodense, with fatty content delimited by a hyperattenuating ring.

Epiploic Appendagitis

Short segment of the colon loop, no thickening of the wall. lesions located in paracolic

\section{Treatment}

The recommended treatment is outpatient with administration of analgesic and anti-inflammatory, with complete improvement of the symptoms around 3 to 14 days. ${ }^{3,7}$ Antibiotic therapy is used in up to $36 \%$ of patients, but its prescription is only indicated in cases of clinical and laboratory suspicion of infection. The Patients who received antibiotics in the study of Freitas et al., the most administered drugs were Amoxicillin-Clavulanate (25\%) and Ciprofloxacin alone or associated with Metronidazole $(75 \%){ }^{3}$

The surgery will only be performed in order to prevent recurrence and adherences adjacent to the site of multiple inflammations, or also when there is no other diagnostic method available. ${ }^{3}$ The laparoscopic removal of the involved appendage consists of simple ligation and excision of inflamed contents. ${ }^{17}$ The possible complications caused by torsion of the untreated Epiploic Appendage consist of peritonitis, intestinal and pericolic obstruction, as well as abscess. ${ }^{25,26}$

\section{Conclusion}

The Epiploic Appendagitis is a benign pathology with a selflimiting course. A detailed clinical examination and an appropriate diagnosis of $\mathrm{AE}$ through examinations of images, preferably $\mathrm{CT}$, allows conservative and outpatient treatment of this pathology. Its correct approach avoids surgical procedures, implying reduction of health expenditures. Its etiology, however, has not been clarified. All clinical or surgical conditions which can evolve to acute inflammatory abdomen represent possible differential diagnoses for EA. For the analysis of the work related to this pathology there is a need for future studies for their full knowledge. 


\section{Acknowledgements}

None.

\section{Conflict of interest}

The author declares that their is no conflict of interest

\section{References}

1. Boscarelli A, Frediani S, Ceccanti S, et al. Magnetic resonance imaging of epiploic appendagitis in children. J Pediatr Surg. 51(12):2123-2125.

2. Sousa D, Ferreira A, Cruz A, et al. Apendagite epiploica-diagnóstio diferencial de apendicite aguda. Rev Port Cir. 2016;36:29-31.

3. Freitas GP, Borges AA, Mendonça R, et al. Apedangite epiploica: aspectos clínicos e radiológicos. Arquivos de.Gastroenterologia. 2008;45(2):163165 .

4. Alves GRT, Silva RVA, Corrêa JRM, et al. Epiploic Appendagitis a challenging imaging diagnosis. Eur J Gen Med. 2012;9(4):283-285.

5. Pinto ICO, Souza LMG, Pessoa LS, et al. Apendicite epiploica, uma breve revião da literatura. Rer Med Minas Gerais. 2011;21(2 Supl 4):S1-113.

6. Hwang JA, Kim SM, Song HJ, et al. Differential diagnosis of left-sided abdominal pain: Primary epiploic appendagitis vs colonic divesticulitis World J Gastroenterol. 2013;19(40):6842-6848.

7. Pignaton G, Borges AA, Mendonça R, et al. Apendagite epiploica: tratamento conservador. Revista Brasileira de Coloproctologia. 2008;28(3):350-351

8. Rashid A, Nazir S, Hakim SY, et al. Epiploic appendagitis of caecum: a diagnostic dilemma. Ger Med Sci. 2010;10.

9. Eberhardt SC, Strickland CD, Epstein KN. Radiology of epiploic appendages: acute appendagitis, post-infarcted appendages, and imaging natural history. Abdom Radiol. 2016;41(8):1653-1665.

10. Schnedl WJ, Krause R, Tafeit E, et al. Insights into epiploic appendagitis Nat Rev Gastroenterol Hepatol. 2011;8(1):45-49.

11. Martinez CAR, Palma RT, Júnior PPS, et al. Primary epiploic appendagitis Journal of Coloproctology. 2013;33(3):161-166.

12. Almeida AT, Melão L, Viamonte B, et al. Epiploic appendagitis: an entity frequently unknown to clinicians - diagnostic imaging, pitfalls, and lookalikes. Am J Roentgenol. 2009;193(5):1243-1251.
13. Han Q, Nair RT, DiSantis DJ. The hyperattenuating ring sign of acute epiploic appendagitis. Abdom Radiol. 2016;41(7):1431-1432.

14. Issa IA, Berjaoui MT, Hamdan WS. Primary epiploic appendagitis: from A to Z. Int Med Case Rep J. 2010;3:67-69.

15. Ammar H, Looney SC, Malani A. Epiploic appendagitis. Lancet. 2009;373(9680):2054.

16. Gourgiotis S, Oikonomou C, Veloudis G, et al. The Diagnostic Dilemma of Primary Epiploic Appendagitis and How to Establish a Diagnosis. Oman Med J. 2016;31(3):235-237.

17. Nadida D, Amal A, Ines M, et.al. Acute epiploic appendagitis: Radiologic and clinical features of 12 patients. Int J Surg Case Rep. 2016;28:219-222.

18. Heise CP. Epidemiology and pathogenesis of diverticular disease. $J$ Gastrointest Surg. 2008;12(8):1309-1311.

19. Matsunaga H, Fujii Y, Taniguchi N. Ultrasonographic findings in epiploic appendagitis. J Med Ultrason. 2010;37(1):31-32.

20. Amo Alonso R, de la Peña Cadenato J, Loza Vargas A, et al. Infarction of the greater omentum. Case report. Rev Esp Enferm Dig. 2015;107(11):706707.

21. Ahn S, Lee H, Choi W, et al. Clinical Importance of the Heel Drop Test and a New Clinical Score for Adult Appendicitis. PLoS One. 2016;11(10):e0164574

22. Ximenes AMG, Mello FST, Lima-Junior ZB, et al. Tempo de internação após apendicectomia aberta por três técnicas cirúrgicas diferentes. $A B C D$ Arq Bras Cir Dig. 2014;27(3):188-190.

23. Thornton E, Mendiratta-Lala M, Siewert B, et al. Patterns of fat stranding. AJR Am J Roentgenol. 2011;197(1):W1-14.

24. Scheer F, Spunar P, Wiggermann P, et al. Mesenteric Panniculitis (MP) in CT - A Predictor of Malignancy? Rofo. 2016;188(10):926-932.

25. Jalaguier A, Zins M, Rodallec M, et al. Accuracy of multidetector computed tomography in differentiating primary epiploic appendagitis from left acute colonic diverticulitis associated with secondary epiploic appendagitis. Emerg Radiol. 2010;17(1):51-56.

26. Aslam MB, Hasan N. Torsion of an appendix epiploica present at the vermiform appendix: a rare cause of acute abdomen. Ulus Trauma Acil Cerrahi Derq. 2009;15(5):509-510. 